DOI: $10.1590 /$ permusi2015a3105

\title{
Fundamentos biomecânicos da postura e suas implicações na performance da flauta
}

\author{
Marcelo Parizzi Marques Fonseca (UFSJ, São João Del Rey, MG) \\ mparizzi@ufsj.edu.br
}

Francisco Cardoso (UFMG, Belo Horizonte, MG)

cardosofe@terra.com.br

Antônio Guimarães (UFSJ, São João Del Rey, MG)
acguima@ufsj.edu.br

Resumo: O estudo sistemático de um instrumento musical não é uma tarefa simples e implica numa demanda física e emocional difícil de imaginar por quem não se dedica a essa atividade. Pesquisadores reconhecem que tal demanda afeta significativamente a carreira do músico instrumentista e pesquisas importantes têm sido conduzidas sobre este assunto. Diante deste contexto, este artigo apresenta um estudo dos fundamentos da biomecânica da postura e suas implicações na performance da flauta. A partir da conceituação da postura normal, considerando o centro de gravidade corporal, a musculatura da estática e a postura normal em pé e sentada, foram elencados os aspectos fundamentais da biomecânica da postura na performance da flauta e as alterações posturais inerentes à sua performance. A conclusão do artigo é que se essas alterações posturais, próprias da performance, não forem conscientizadas pelo flautista, a qualidade da execução e a longevidade de sua carreira poderão ficar seriamente comprometidas.

Palavras-chave: Música e biomecânica; postura; flauta; performance; saúde do músico.

The fundamentals of posture's biomechanics and their implications on the performance of the flute

\begin{abstract}
The systematic practice of a musical instrument is not a simple issue and involves physical and emotional demands which are difficult to understand by those who are not engaged with this activity. Researchers recognize that such demand may significantly affect the musician's career. Important studies have been conducted on this subject. Given this context, this paper presents a study of the fundamentals of the posture's biomechanics and their implications on the performance of the flute. From the concept of normal posture (gravity of body center, the static muscle, and the normal posture - standing and seated), the fundamental aspects of the posture's biomechanics during flute's performance, and the inherent postural changes in this performance were considered. Results show that if the flutists unaware of the inherent postural changes during the flute's performance, may have the quality of his performance and the longevity of his career seriously compromised.
\end{abstract}

Keywords: biomechanics and music; posture; flute; performance; health of the musician.

\section{1 - Introdução}

Tocar um instrumento musical é tido, pelo senso comum, como algo eminentemente lúdico, destituído de qualquer risco, mas essa não é a realidade observada entre os músicos profissionais. O estudo sistemático de qualquer instrumento musical não é uma tarefa simples e implica numa 
demanda física e emocional difícil de imaginar por quem não se dedica a essa atividade. Muitos pesquisadores reconhecem que tal demanda afeta significativamente a carreira do músico instrumentista e pesquisas importantes têm sido conduzidas sobre este assunto (TEIXEIRA, 2011; MERRIMAN et al, 1986; CRASKE; CRAIG, 1984; FRY, 1986a, 1986b; VALENTINE et al, 1995; STEPTOE, 1989; STEPTOE; FIDLER, 2001; DAWSON, 2001: WARRINGTON et al, 2002; SAKAI, 1992, 2002; SANTIAGO, 2001, 2004, 2005, 2006, 2008; COSTA, 2005; CAMPOS, 2006; ALVES, 2007; FONSECA J.G., 2007).

\begin{abstract}
A performance musical é provavelmente a mais complexa de todos as habilidades motoras porque combina criatividade artística, expressão emocional e interpretação musical com um elevado nível de controle sensório-motor, destreza, precisão, competência muscular, velocidade e estresse de performance (WILSON, 1989).
\end{abstract}

Essa citação traduz de modo eloquente a complexidade do ato de tocar um instrumento musical com destreza, o que, repetimos, é muito difícil de ser percebido por alguém que não toca um instrumento musical. ERICSSON et al (1993) e SHENK (2010) estimaram, observando estudantes de violino do Conservatório de Berlim, que um estudante não atingirá um grau satisfatório de performance antes de sete mil horas de prática consciente do instrumento. Isso significa que uma pessoa, pedagogicamente bem orientada, necessita estudar com dedicação integral (6 horas/dia em média - 5 dias por semana) pelo menos seis a sete anos para atingir um nível técnico que lhe permita almejar uma carreira de solista. Se for considerada a performance de artistas de altíssimo nível, pode-se aumentar ainda mais essa demanda de horas de estudo.

O estudo de um instrumento musical demanda dois tipos complementares de trabalho: o biomecânico e o musical.

$\mathrm{Na}$ performance da flauta, o trabalho biomecânico significa o treinamento das seguintes técnicas: sustentação da flauta; embocadura (posicionamento dos lábios de um modo específico para direcionar a coluna de ar contra o bocal); respiração; do posicionamento da cabeça, pescoço, ombros, tronco, braços, mãos, quadril, pernas e pés e compreensão do equilíbrio postural geral durante a performance. $O$ trabalho biomecânico permite ao flautista o desenvolvimento de técnicas de performance que vão possibilitar o desenvolvimento daquilo que se chama de trabalho musical (TEIXEIRA, 2011; HUNT, 2007; FONSECA M.P.M., 2005, 2007, 2008, 2010; DEBOST 2002; HARRISON, 1983).

O trabalho musical significa o treinamento das técnicas que permitem a produção do som em todas suas nuances musicais necessárias à performance, o que inclui o controle da afinação, capacidade de produzir sons graves, médios e agudos (registros sonoros), homogeneidade sonora, vibrato, mudanças de timbre e a habilidade de executar escalas, arpejos e diferentes articulações (DEBOST, 2002; GRAF, 1991; RANEVSKY, 1999; TAFFANEL e GAUBERT, 1958; MOYSE, 1934). 
É importante, nesse momento, salientar duas questões: (1) a distinção entre esses dois tipos de trabalho (musical e biomecânico) é essencialmente um recurso pedagógico que facilita sua compreensão; na prática da performance, eles são indissociáveis e, apesar disso, (2) a maior parte dos métodos e tratados de técnica de performance enfatiza a dimensão musical da técnica, em detrimento das dimensão biomecânica (ALMEIDA et al, 2009; GRAF, 1991; TAFFANEL e GAUBERT, 1958; MOYSE, 1932, 1934).

Pela extensão e complexidade do assunto, este artigo tratará exclusivamente do trabalho biomecânico, com ênfase nas questões relacionadas à postura corporal do flautista, ou seja, o posicionamento da cabeça, pescoço, ombros, tronco, braços, mãos, quadril, pernas e pés e a compreensão do equilíbrio postural geral durante a performance. Não será abordada neste artigo a respiração na performance da flauta.

\section{2 - Biomecânica da Postura 2.1 Conceituação de postura}

A preocupação sistemática com a postura corporal data do inicio do século XIX, quando médicos e outros profissionais começaram a se preocupar com 0 assunto e a se indagar sobre como o homem consegue se manter em pé (BRICOT, 2001). A primeira escola de Posturologia foi fundada em Berlim em 1890 e, apesar de ser motivo de estudo há tanto tempo, a postura continua sendo um dos termos mais complexos de se definir, mesmo quando se restringe à sua dimensão musculoesquelética.

Nesse trabalho será utilizada a definição de postura corporal em seu sentido biomecânico, como a resultante do conjunto de forças musculares que atuam continuamente para compensar o efeito da gravidade (e de outras forças desequilibradoras) sobre o corpo e que permitem o alinhamento dos vários segmentos corporais de modo anti-gravitacional, possibilitando a manutenção da posição ereta, assentada ou de qualquer posição que demande a sustentação anti-gravitacional de um segmento corporal. Além de seu papel de sustentação, essas forças musculares contribuem decisivamente na manutenção de nossa consciência têmporo-espacial (TEIXEIRA, 2011; BRICOT, 2001; KENDALL et al, 1995).

A postura corporal é considerada adequada quando essas forças que sustentam o corpo atuam sem geração de sobrecargas, com a máxima eficiência e o mínimo de esforço, mantendo um alinhamento funcionalmente eficaz dos vários segmentos corporais. A postura adequada facilita os movimentos corporais (SANTIAGO, 2001, 2004, 2008; BRICOT, 2001; DOMMERHOLT, 2000).

A postura é considerada inadequada, quando a manutenção do corpo em situação anti-gravitacional implica na utilização excessiva ou desnecessária de 
forças musculares e em alinhamentos disfuncionais. As posturas inadequadas dificultam os movimentos (TEIXEIRA, 2011; FONSECA M.P.M., 2005, 2007, 2008, 2010; FONSECA J.G., 2008; DEBOST, 2002; BRICOT, 2001; ANDRADE e FONSECA, 2000; ZAZA, 1998).

A observação da qualidade do alinhamento dos segmentos corporais é o principal recurso objetivo para avaliação da adequação da postura.

\subsection{Aspectos fundamentais da biomecânica da postura corporal na performance da flauta}

\subsubsection{A "estática" - base para o conceito de postura normal}

A postura estática é a postura do corpo em pé parado. A manutenção do equilíbrio na posição ereta depende da atuação da chamada "musculatura da estática" (Ex.1).
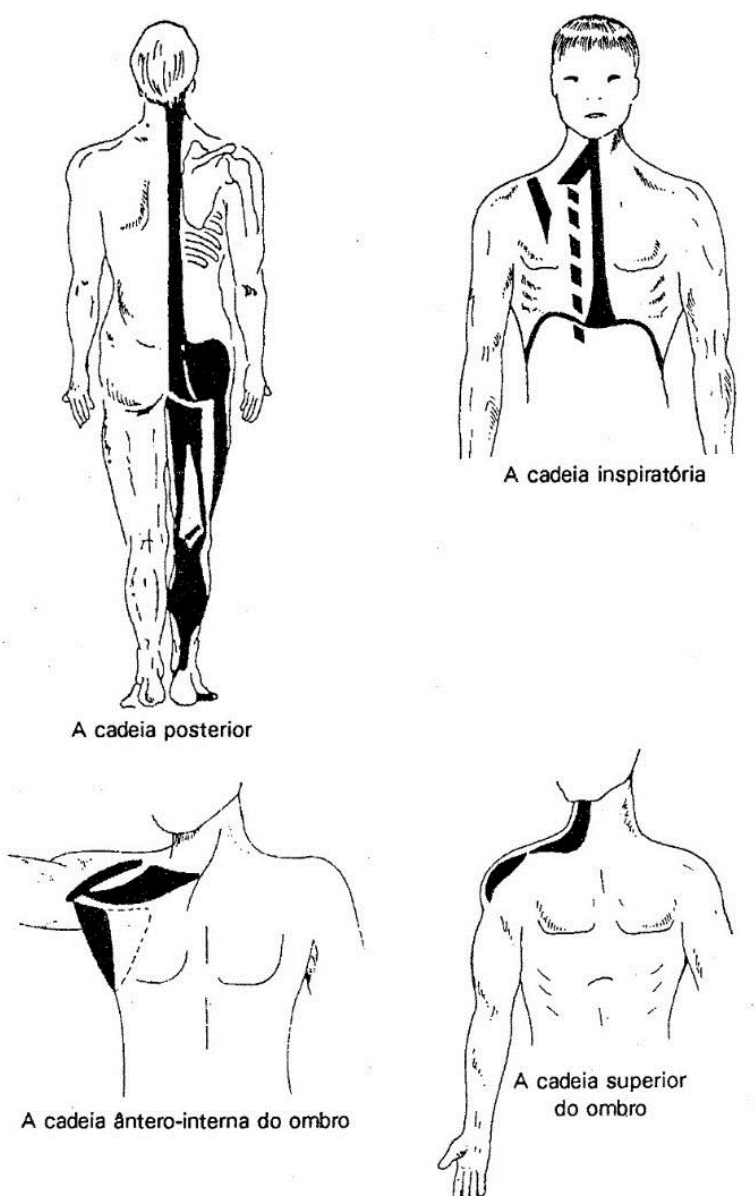

Ex.1 - Figura da "musculatura da estática"; em preto os conjuntos musculares posteriores e anteriores responsáveis pela manutenção da postura ereta (FONSECA M.P.M., 2005, 2007, 2008, 2010; SOUCHARD, 1989). 
Esse conjunto de músculos (com seus ligamentos e fáscias - as membranas que revestem os músculos), juntamente com os ossos e as articulações da coluna vertebral, são os principais responsáveis pela manutenção da postura ereta e são fundamentais para a qualidade (melhor ou pior) dos movimentos corporais. (AMADIO, 2003; BARCELLOS, 2002; BRICOT, 2001; ANDRADE e FONSECA, 2000; ZAZA, 1998; HORAK et al, 1996).

O conhecimento das bases biomecânicas da postura estática é fundamental para a compreensão do equilíbrio corporal na performance da flauta. A metáfora do corpo dividido em blocos ou conjuntos segmentares é muito útil para um entendimento mais claro da postura estática (MENEGATTI, 2011; DUARTE et al, 2002).

Os membros inferiores se constituem na base sólida em contato com o chão. Sua posição condiciona qualidade da base de sustentação. As variações dessa base e, principalmente, sua estabilidade são elementos capitais da estática. Os pés são estruturas determinantes; sem bons apoios dos pés no chão, não há estabilidade estática. Na performance da flauta o bom apoio dos pés é fundamental para o equilíbrio corporal. Entretanto, MATHIEU (2004) afirma que os flautistas devem manter a ideia de "conjunto de gestos corporais" durante a performance. Uma postura fixa, na qual o flautista se mantenha imóvel, mesmo com um bom apoio dos pés pode ser prejudicial. Os flautistas devem ora distribuir o peso do corpo igualmente entre os dois pés, ora oscilar o peso do corpo entre um pé e outro (FONSECA M.P.M., 2005, 2007, 2008, 2010; BIENFAIT, 2000; BARKER, 1991).

O equilíbrio dos joelhos está intimamente ligado ao dos pés numa relação ascendente e ao quadril numa relação descendente. Esses dois primeiros conjuntos segmentares - pés e joelhos - são importantes determinantes do equilíbrio estático (FONSECA M.P.M., 2005, 2007, 2008, 2010; BIENFAIT, 2000; BARKER, 1991).

Cada conjunto segmentar equilibra-se sobre o subjacente numa relação ascendente. $O$ pé equilibra-se e adapta-se sobre o chão; a perna, sobre o pé; a coxa, sobre a perna; a bacia (cintura pélvica) sobre os membros inferiores; a coluna lombar sobre a bacia; a coluna torácica sobre a lombar; e a cervical sobre a torácica (FONSECA M.P.M., 2005, 2007, 2008, 2010; BIENFAIT, 2000; BARKER, 1991).

A cabeça tem dois imperativos biomecânicos indispensáveis: a verticalidade dela mesma e a horizontalidade do olhar. O pescoço (coluna cervical), os ombros e os membros superiores devem adaptar-se a esses imperativos num equilíbrio descendente.

A postura estática é assegurada por dois grandes sistemas: um ascendente - 0 equilíbrio estático garantido pelos membros inferiores e pelo tronco, e um descendente - garantido pelo pescoço, cabeça e tronco. $O$ tronco, como 
segmento comum aos dois sistemas, é separado dos outros componentes de cada sistema (pescoço-cabeça e membros inferiores) por dois segmentos intermediários: as cinturas. A cintura pélvica (bacia) adapta o tronco aos membros inferiores, e a cintura escapular (dos ombros) adapta o tronco à região do pescoço e cabeça. O tronco é assim a região de todas as compensações estáticas.

\subsubsection{O centro de gravidade corporal}

Como já mencionado no item anterior quando definimos postura, o corpo é continuamente atraído pela gravidade. Para que ele possa se sustentar em qualquer postura, é necessária uma força anti-gravitacional, feita pelos músculos. A resultante entre estas duas forças opostas chama-se centro de gravidade corporal. A posição do centro de gravidade do corpo humano depende da posição do corpo. Em posição ereta, o centro de gravidade pode ser representado por um eixo central, que divide o corpo em 2 partes, quando visto de frente; já quando o corpo é visto de perfil, o centro de gravidade pode ser representado por uma linha vertical que passa pelo osso mastóide, imediatamente atrás da orelha e pelo tornozelo. Posturas inadequadas deslocam o centro de gravidade e representam sobrecarga muscular.

A performance da flauta implica em pequenos deslocamentos do eixo de gravidade. A consciência do eixo de gravidade é fundamental para que os flautistas possam minimizar estes deslocamentos e evitar uma sobrecarga muscular excessiva (TEIXEIRA, 2011; FONSECA, MPM, 2005, 2007, 2008, 2010; BIENFAIT, 2000; GARDINER 1986).

\subsubsection{A postura normal em pé}

A postura ereta normal depende de relações harmoniosas e funcionalmente eficazes entre os vários segmentos corporais. A avaliação objetiva da postura implica na observação do corpo em três planos: frontal (Ex.3), lateral ou de perfil (Ex.2) e superior ou visto de cima (Ex.4). 


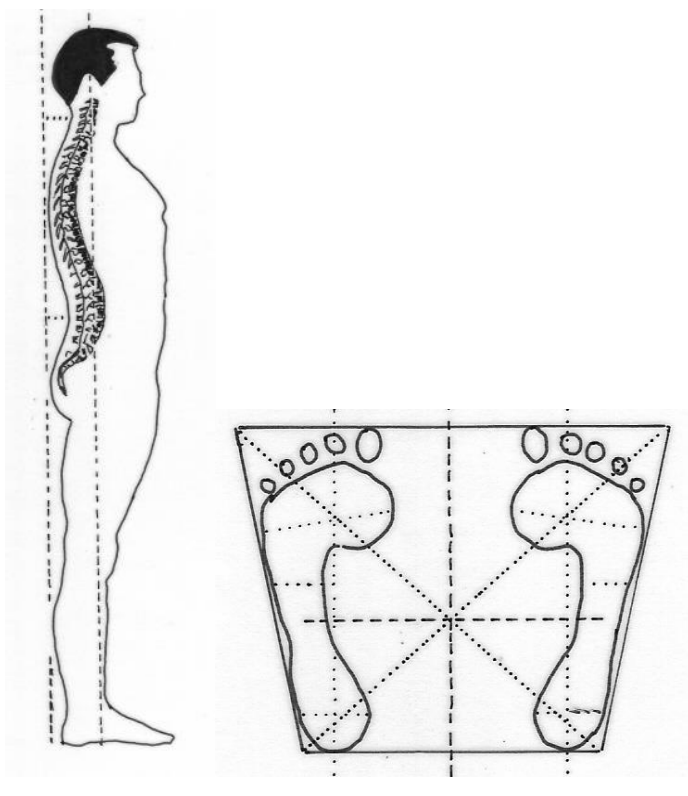

Ex.2 - Figura da postura normal em perfil (FONSECA M.P.M., 2005, 2007, 2008, 2010; BRICOT; 2001).

São as seguintes as características da postura normal quando o corpo é visto de perfil (Ex.2)

- planos escapular e das nádegas alinhados;

- o vertex (região mais alta do crânio), a apófise odontóide da segunda vértebra do pescoço e o corpo vertebral da terceira vértebra lombar estão alinhados;

- centro do quadrilátero de sustentação equidistante dos pés;

- presença de discreta lordose lombar (curvatura da parte mais baixa da coluna);

- a linha vertical que passa pelo tragus (pequena saliência na entrada da orelha) deve cruzar os maléolos (saliências óssea dos tornozelos) ou muito próximo deles;

- a distância entre a protuberância occipital (saliência mais posterior do crânio) e o plano posterior do corpo deve ser de dois a três centímetros. 


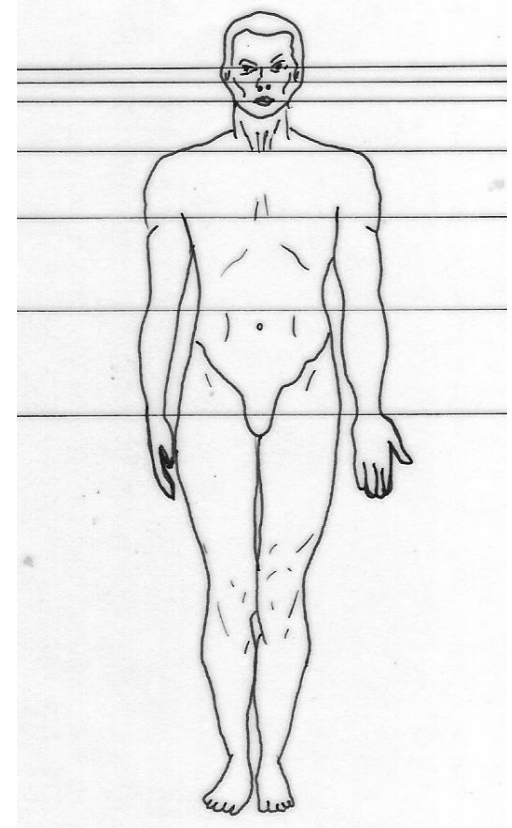

Ex.3 - Figura da postura normal de frente (FONSECA M.P.M., 2005, 2007, 2008, 2010; BRICOT, 2001).

A figura do Ex.3 mostra as linhas imaginárias traçadas entre as pupilas, os tragus, os dois mamilos, a cintura escapular (dos ombros) e a cintura pélvica (bacia); na postura normal no corpo visto de frente, essas linhas devem ser paralelas ao chão. Além disso, os pés devem apoiar no solo de forma simétrica.

Numa visão de cima (Ex.4) as nádegas devem estar no mesmo plano e as pontas dos dedos com as mãos estendidas devem tocar o mesmo plano, sem que haja rotação dos ombros e da bacia.

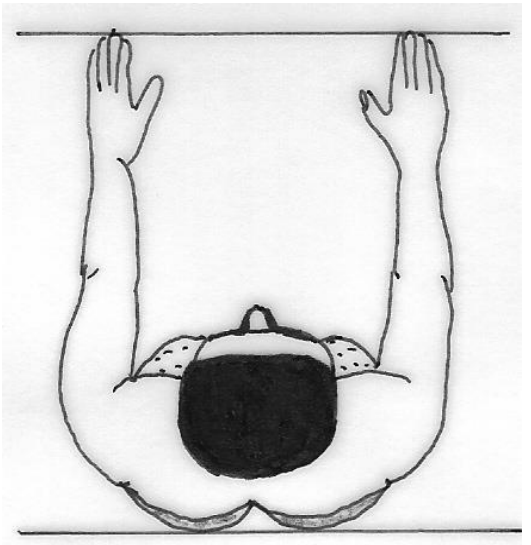

Ex.4 - Figura da postura normal vista de cima (FONSECA M.P.M., 2005, 2007, 2008, 2010; BRICOT, 2001) 


\subsubsection{A Postura Sentada}

A posição sentada faz parte do cotidiano das pessoas em geral e é essencial na prática e performance da flauta. Apesar de o homem moderno chegar a passar muitas horas nesta posição, o modelo biomecânico da coluna humana não foi feito para permanecer por longos períodos na posição sentada. Quando associada a uma má postura, e mobiliário inadequado, a posição sentada prolongada pode sobrecarregar a coluna vertebral e predispor a uma série de problemas físico-posturais que chega a acometer cerca de $80 \%$ das pessoas (RUMAQUELLA et al), 2008, LIDA 2005, BRACCIALLI \& VILARTA 2000, MORO 2000).

A coluna vertebral é o eixo do corpo e concilia dois aspectos mecânicos contraditórios: a rigidez e a flexibilidade. A flexibilidade do eixo vertebral se deve à sua configuração por múltiplas peças superpostas, unidas entre si por elementos ligamentares e musculares. Deste modo, esta estrutura pode deformar-se apesar de permanecer rígida sob a influência dos tensores musculares.

A coluna vertebral consiste de 24 vértebras individualizadas mais os ossos sacro e cóccix que são o resultado da fusão originária de vértebras. Quando observada lateralmente, a coluna apresenta quatro curvaturas: a curvatura sacral (que é fixa e de concavidade anterior), a lordose lombar (de concavidade posterior), a cifose dorsal (de convexidade posterior) e a lordose cervical de concavidade posterior (RUMAQUELLA et al, 2008; PEQUINI, 2005; MORO 2000).

Durante a postura sentada quase todo o peso do corpo passa a ser suportado pela musculatura do dorso e do ventre. Nesta posição a lordose lombar é reduzida, fazendo com que o espaço existente na porção anterior das vértebras diminua e o espaço da porção posterior aumente e, desta forma o núcleo pulposo que estava no centro do disco, seja empurrado para trás causando um aumento de pressão dentro deste núcleo intervertebral e o estiramento das estruturas posteriores da coluna, ligamentos, articulações, músculos e nervos.

Outro aspecto importante que deve ser ressaltado é a mensuração da pressão intradiscal nas posições em pé, sentada e deitada. Pode-se constatar que na posição sentada a pressão varia entre $140 \%$ a $190 \%$ sendo mais prejudicial que a posição em pé (pressão $=100 \%$ ) e a posição deitada (pressão $=24 \%$ ) (RUMAQUELLA Et all, 2008; COURY, 1995; GRANDJEAN, 1998).

MORO (2000) classifica, a partir da posição do centro da gravidade do corpo, a posição sentada em três categorias (Ex.5):

- Posição anteriorizada - nesta, o centro da gravidade está logo à frente das tuberosidades isquiáticas e mais de $25 \%$ do peso é transmitido ao solo pelos pés. A postura é assumida com a inclinação à frente do 
tronco, de forma a apresentar uma cifose dorsal mais pronunciada e sem ou com pouca rotação da pelve.

- Posição média - o centro da gravidade esta diretamente acima das tuberosidades isquiáticas e apenas $25 \%$ do peso corporal é transmitido ao solo através dos pés. Desta forma, com o corpo relaxado, a coluna lombar se mantém alinhada ou com uma leve cifose.

- Posição posteriorizada - o centro da gravidade se localiza atrás das tuberosidades isquiáticas e menos de $25 \%$ do peso do corpo é transmitido ao solo pelos pés. O tronco inclina-se para trás concomitante à rotação da pelve e desta forma, aumentando a cifose dorsal.

Segundo esse autor (MORO 2000) a posição média é a mais eficiente sob o ponto de vista biomecânico e, por isso, a mais adequada.

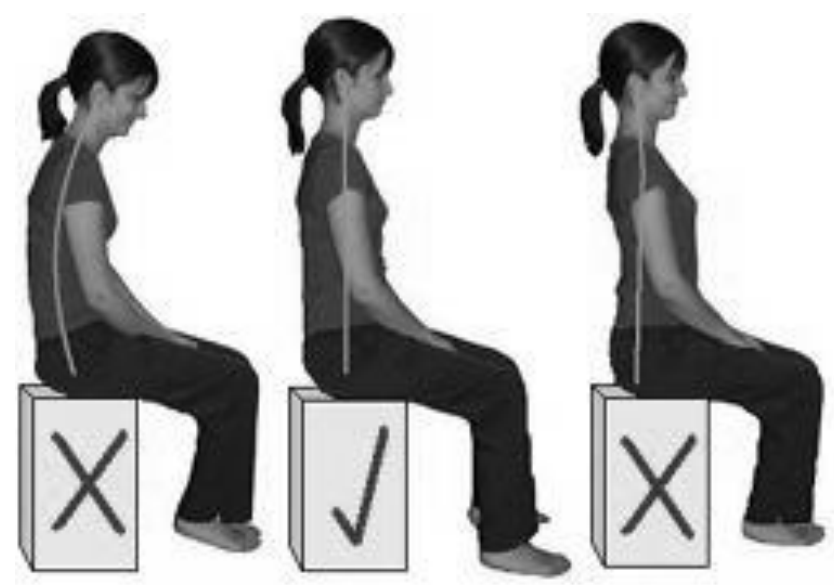

Ex.5 - Figura da posição anteriorizada, posição média e posição posteriorizada, respectivamente (RUMAQUELLA, 2008; LIDA, 2005; PEQUINI, 2005; MORO, 2000).

Para NEUMANN (2006) a associação do ficar assentado por longos períodos à falta de consciência corporal e a um mobiliário inadequado, trará muito provavelmente alterações nas curvaturas da coluna, protusão da cabeça, diminuição da expansão diafragmática e aumento da tensão muscular o que acarretará problemas posturais potencialmente graves.

\section{3 - A Postura na performance da flauta}

\subsection{Considerações históricas}

Embora seja muito antiga, não é freqüente, na literatura especializada, a preocupação com a postura na performance da flauta (THOMPSON, 2008; FONSECA, 2005, 2007, 2008, 2010). Johann Joachim Quantz (1697-1773), grande compositor e flautista alemão do século XVII, foi um dos primeiros autores que manifestou preocupação sistemática com questões técnicas relacionadas à postura na execução da flauta. Esse autor/compositor tratou detalhadamente, em seu tratado Essay of a Method for Playing The Transverse 
Flute (1752), de assuntos fundamentais como a sustentação do instrumento, a posição das mãos, a embocadura e a respiração. A ênfase que ele dá a essas questões mostra sua preocupação com a postura do flautista. No capítulo que trata da sustentação da flauta, ele afirma que:

A cabeça deve se sustentar sempre ereta, e de maneira natural, assim a respiração não será prejudicada. Você deve sustentar seus braços um pouco afastados de seu corpo, o esquerdo um pouco mais que o direito, e não pressioná-los contra o corpo, afim de que sua cabeça não fique em uma posição oblíqua em relação ao seu corpo; isso poderia, além de causar uma má postura, impedir sua respiração, uma vez que sua garganta se contrairia e a respiração não aconteceria tão facilmente como deveria ser. Você deve sempre sustentar a flauta com firmeza contra sua boca, a alternância desta pressão pode afetar a afinação (QUANTZ, 1752, p.37).

Métodos consagrados como Méthode complète de Flûte, de Taffanel e Gaubert (1958, p.4) e Check-up - 20 Basic Studies for Flautists de Peter Lukas Graf (1991, p.4) são unânimes em afirmar que a postura correta é essencial para a técnica do instrumento. Nenhum desses autores, no entanto, é claro quanto à técnica para se atingir esses objetivos. Eles tendem a tratar essas questões de forma superficial, dificultando sua compreensão.

Apenas mais recentemente a preocupação com uma postura adequada vem sendo relevada por vários autores embora ainda não possamos dizer ainda que se trata de uma preocupação sistemática. Reproduzimos aqui algumas afirmações nesse sentido de autores:

KIMACHI (2002) detalha a técnica necessária para uma postura adequada:

Quando de pé, devemos pensar em uma postura relaxada, ereta, com cabeça e tronco erguidos, joelhos levemente dobrados, peso nas coxas, sensação de uma linha imaginária que vai do calcanhar, passando pelas costas e indo até a cabeça, alongando o corpo inteiro. Para deixar a cabeça na posição certa, não muito abaixada e nem muito erguida, podemos fazer um teste, cantando e sustentando a vogal $\hat{O}$ e abaixando e erguendo a cabeça sucessivamente. Devemos procurar o som mais ressonante e aberto, indicando que estamos abrindo a garganta e com a postura correta. A sensação é de alongamento da coluna cervical (região do pescoço). Os braços formam triângulos com o corpo. Se fôssemos vistos de cima, veríamos dois triângulos cujos lados seriam formados pelos braços, antebraços e corpo. Devemos sempre pensar em relaxar os ombros. $O$ quanto levantamos ou abaixamos os cotovelos e o quanto dobramos os pulsos devem estar relacionados com o relaxamento dos ombros e o alinhamento da flauta com relação ao corpo. Vendo um flautista de frente, a linha do instrumento deve ser paralela com a linha dos lábios. Vista de cima, a linha da flauta deve estar perpendicular à ponta do nariz do músico.

Os pés podem ficar paralelos um ao outro ou fazendo um "L", o direito sendo a base e o esquerdo à frente, levemente separados. Giramos a cabeça para esquerda em direção à estante, ao maestro e ao público.

Nosso corpo nunca ficará de frente para a estante e sim para a direita. $O$ mesmo vale quando estamos sentados. Os pés devem tocar o chão, e a 
cadeira voltada para a direita para girarmos a cabeça para a esquerda. A flauta é transversal, não a tocamos como um clarinete, por exemplo. Se não prestarmos atenção a estes detalhes, podem-se desenvolver graves problemas de coluna. Devemos pensar em movimentos horizontais, seguindo as linhas das frases, para não criarmos vícios de tocar acentuando notas sem necessidade, a menos que estejam indicados acentos na partitura. Os movimentos devem estar sempre relacionados à música, como se fôssemos atores interpretando um texto.

D'ÁVILA (2003), trata da postura do flautista enfatizando a auto-observação durante a performance.

Creio que a primeira coisa para ser refletida em relação à postura do corpo do flautista quando este está executando seu instrumento é: embora a postura assumida pelo flautista - quando este está executando seu instrumento - não seja a postura mais natural para o ser humano executar um instrumento, ela PODE e DEVE tornar-se a mais natural possível.

A partir desta reflexão, o primeiro passo para se obter uma boa postura além de receber boas orientações do professor - é estar sempre muito atento na utilização do próprio corpo, sobretudo quando este está atuando na execução. Este processo de auto-observação deve ser auxiliado, sempre que possível, pela utilização de um espelho (de proporções mínimas que possam refletir a imagem de todo o corpo do flautista) ou pela utilização de uma câmara de vídeo, ferramenta nem sempre acessível a todos, mas que pode trazer ótimos benefícios, ainda que utilizada esporadicamente.

\subsection{A sustentação da flauta}

MATHIEU (2004) afirma que a primeira grande dificuldade colocada pela flauta é segurá-la. Manter um objeto no eixo do corpo é mais fácil do que mantê-lo de lado. A sustentação da flauta desvia as forças de sustentação para a direita. Este desvio propicia uma maior carga de trabalho da musculatura e, na opinião dessa autora, os flautistas que não se preocupam com o conjunto de seus gestos, podem chegar a uma postura marcada por muitas tensões que se instalam para compensar os desvios dos eixos corporais. Estas tensões se insinuam sutil e sucessivamente, e acabam por se fixar no esquema de gestos dos músicos. O "esquema motor" assim instalado torna-se uma espécie de programa cerebral disparado a partir do momento em que o músico pega seu instrumento.

A sustentação da flauta é feita por três pontos de apoio que deverão atuar como forças contrárias para permitir uma boa estabilidade do instrumento durante a performance. O primeiro ponto de apoio é a falange proximal do dedo indicador da mão esquerda que se posicionará entre as duas primeiras chaves da flauta (Dó e Dó sustenido). Este apoio pressiona a flauta contra o queixo na altura do lábio inferior do flautista (PEARSON, 2002; DEBOST, 2002; FUKS, 2000; WURZ, 1998; HARRISON, 1983).

O segundo ponto de apoio é o dedo polegar da mão direita que irá pressionar a flauta em uma direção contrária do primeiro ponto de apoio. Estas duas forças 
antagônicas devem se equilibrar quando o bocal se posiciona entre protuberância mentual (a ponta do queixo) e o lábio inferior do flautista.

A flauta é um instrumento completamente sustentado pelo flautista durante 0 estudo e a performance, e, de maneira semelhante ao violino, é um instrumento que exige para ser sustentado um certo grau de assimetria postural do tronco. Além da assimetria postural, a sustentação da flauta exige forças isométricas da musculatura por períodos prolongados de tempo o que, inevitavelmente representa sobrecarga postural, principalmente para a região da cintura escapular, pescoço e membros superiores e pode contribuir para a tendência de desalinhamento postural crônico (TEIXEIRA, 2011; FONSECA 2005, 2007, 2008, 2010; THOMPSON, 2008; VISENTIN e SHAN, 2003; QUEIROZ e FONSECA, 2000).

\subsection{Alterações posturais decorrentes da performance da flauta}

Um indivíduo normal com boa postura, quando visto de perfil, tem os planos das escápulas e o dos glúteos alinhados (Ex.6).

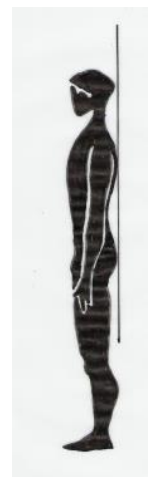

Ex.6 - Figura da postura normal em perfil (FONSECA M.P.M., 2005, 2007, 2008, 2010; BRICOT, 2001)

Ao segurar a flauta, ocorre com muita frequência o deslocamento do pescoço para frente e o desalinhamento do plano escapular (Ex.7).

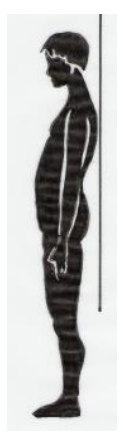

Ex.7 - Figura do plano escapular posteriorizado e a projeção do pescoço (FONSECA M.P.M., 2005, 2007, 2008, 2010; BRICOT, 2001). 
Visto de frente, o flautista tende a desalinhar todas as linhas horizontais: linhas das pupilas, entre os dois tragus, entre os dois mamilos, além das cinturas escapular e pélvica. Como já visto anteriormente, o Ex.3 ilustra a postura normal vista de frente. O Ex.8 e o Ex.9 ilustram os desalinhamentos mais comuns durante a performance da flauta.

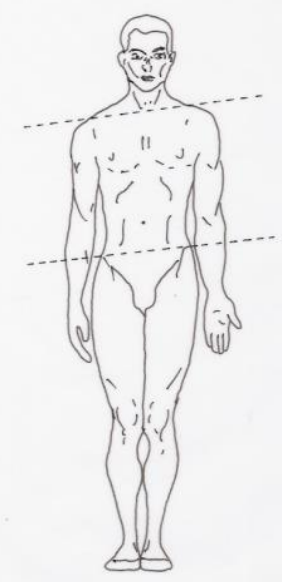

Ex.8 - Figura das básculas paralelas de ombros e quadril (FONSECA M.P.M., 2005, 2007, 2008, 2010; BRICOT, 2001).

Ex.9 - Figura das básculas cruzadas de ombros e quadril (FONSECA M.P.M., 2005, 2007, 2008, 2010; BRICOT, 2001). 
Visto por cima, um flautista tende a desalinhar os ombros colocando o ombro esquerdo na frente do direito.

Estes desalinhamentos, que perturbam a estática, são inerentes ao ato de tocar flauta e merecem toda a atenção no sentido de serem minimizados durante a performance e compensados com cuidados posturais no cotidiano em geral. Flautistas que não desenvolvem a consciência desses desalinhamentos e não cuidam de suas compensações, tendem a apresentar dores, enrijecimentos, contraturas, com limitação dos movimentos articulares, queda no rendimento e na resistência musculares, que acabam por prejudicar seriamente a qualidade da performance e da progressão do aprendizado (TEIXEIRA, 2011; FONSECA M.P.M., 2005, 2007, 2008, 2010; MATHIEU, 2004).

Numa tentativa inconsciente de compensar o problema da assimetria e do peso do instrumento, os flautistas tendem, muitas vezes, a recuar posteriormente o ombro direito e avançar o esquerdo em um movimento de rotação dos quadris, para, com isso, ajustar melhor o bocal e atingir as chaves na outra extremidade (Ex.10). O cansaço faz com que o flautista aproxime o instrumento de seu ombro direito para aliviar o desgaste de sustentá-la com o braço. Alguns flautistas chegam mesmo a inclinar o tronco para o lado (direito) para apoiar o cotovelo no tronco, numa situação de virtual colapso postural. "A postura fica totalmente caída para escapar do peso da flauta" (TEIXEIRA, 2011; FONSECA M.P.M., 2005, 2007, 2008, 2010; MATHIEU, 2004).

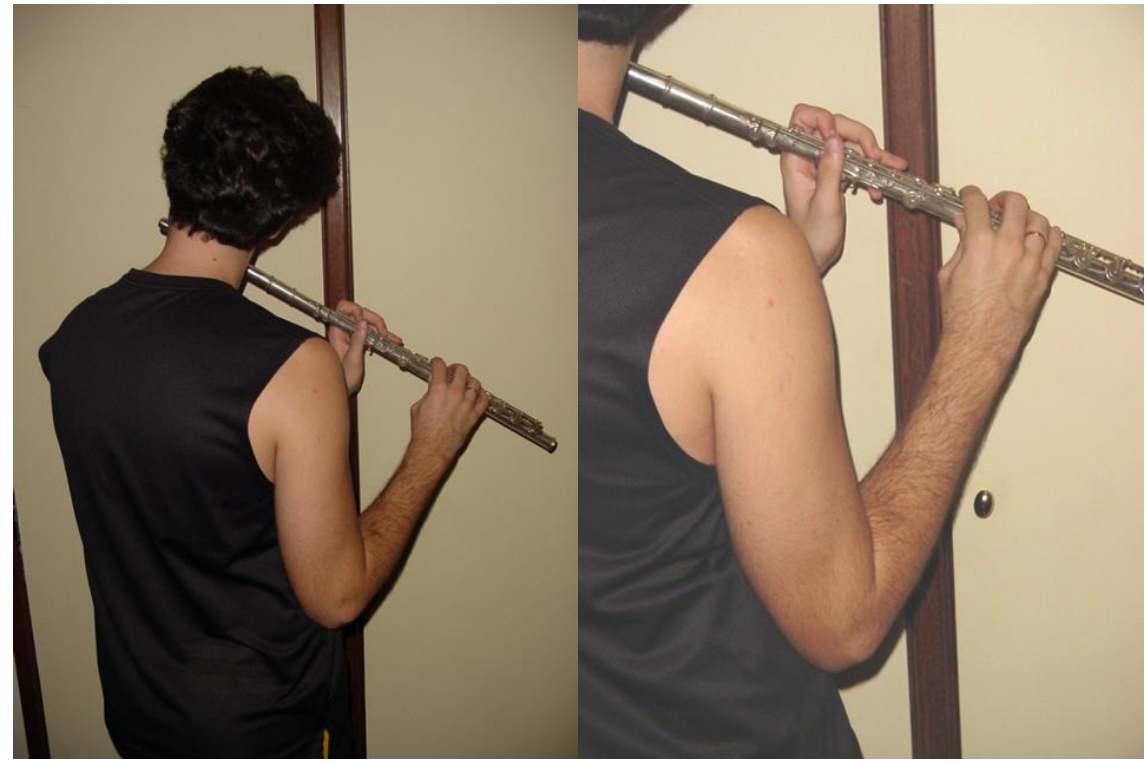

Ex.10 - Figura de colapso postural frequente em flautistas: apoio do cotovelo direito no tronco para aliviar o peso do instrumento e rotação do pescoço (ACKERMANN et al, 2011; FONSECA M.P.M., 2005, 2007, 2008, 2010; MATHIEU, 2004) 
Esta postura dificulta a ação dos músculos respiratórios e obriga o flautista a virar a cabeça para o lado esquerdo para ler a partitura. Além disso, esta posição faz com que a cabeça fique bastante inclinada acabando com a horizontalidade do olhar, promovendo desconfortos físicos.

Para alguns flautistas que assumem essa postura com grande frequência, NORRIS (1997) propõe o uso de um bocal angulado desenvolvido pela Emerson Musical Instruments (Ex.11). Este bocal permite que o flautista toque de maneira mais confortável e ameniza a problemática postural da performance. Contudo, há uma perda da estabilidade do instrumento e, por isso, ele aconselha o uso de um acessório para apoiar o polegar da mão direita e o indicador da mão esquerda.

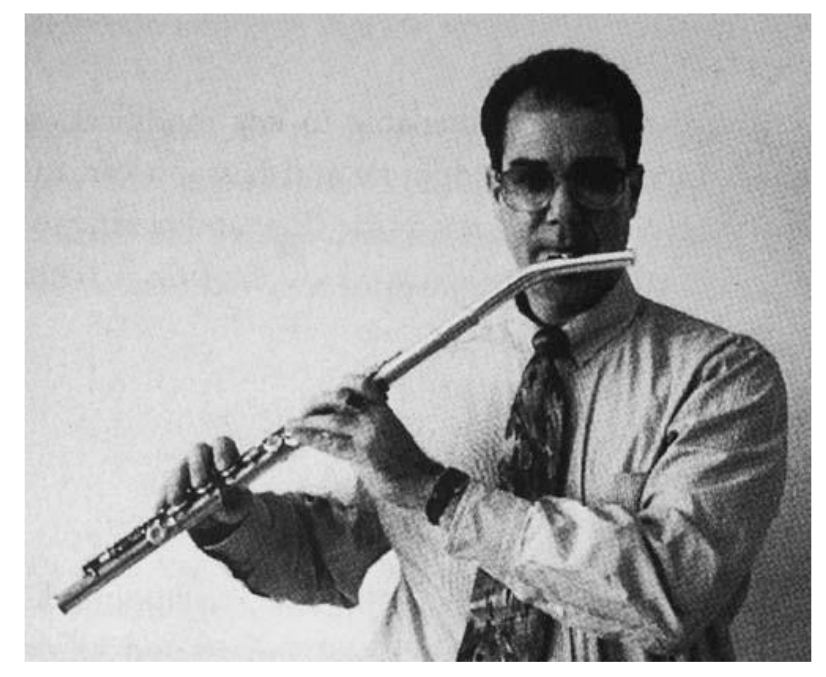

Ex.11 - Figura do bocal angulado desenvolvido pela Emerson Musical Instruments.

Considerando a prática musical orquestral como uma das principais facetas profissionais dos flautistas, torna-se importante uma abordagem sobre a performance da flauta na posição sentada. A rotina dos instrumentistas de orquestra inclui apresentações frequentes de repertórios variados, viagens e longas horas de preparação e ensaios. Normalmente nesta rotina, os músicos ficam na posição sentada a qual exige, de uma maneira geral, uma maior demanda da coluna cervical e das demais estruturas ósseas e musculares.

É necessária muita atenção, pois este somatório (maior demanda da coluna cervical e das demais estruturas ósseas e musculares associada aos desvios posturais inerentes à performance da flauta) pode resultar em uma série de problemas físico-posturais e também técnico-musicais. MCGILL (2002) recomenda a mudança de postura e momentos de pausa para possibilitar maior movimentação corporal. Vale ressaltar a influencia que o encosto das cadeiras tem sobre a postura sentada. RUMAQUELLA (2008) afirma que "ao se sentar com apoio ocorre uma diminuição da pressão intradiscal e da ação muscular, pois parte do peso ósseo é transferido para o encosto da cadeira”. É 
importante que seja pesquisado o tipo de mobiliário ergonômico adequado para cada tipo de profissão (ACKERMANN, 2011; TEIXEIRA, 2011; BRODSKY, 2006; FONSECA M.P.M., 2005, 2007, 2008, 2010; FONSECA J.G., 2008; WILLIAMON, 2006, 2004; MATHIEU, 2004; BRODSKY, 2006; WYNN, 2004; DAWSON, 2001; ANDRADE e FONSECA, 2000; NORRIS, 1997).

\section{4 - Conclusões}

A partir dos conceitos apresentados, é possível concluir que grande parte das definições de postura enfatiza a relação da boa postura com a ideia de movimento ou conjunto de gestos. Uma postura inadequada pode produzir deslocamentos no eixo de gravidade do corpo resultando em sobrecarga dos músculos e articulações (BRODSKY, 2006; MATHIEU, 2004; BRICOT, 2001; KENDAL, 1995).

Quando a musculatura da estática permanece longo tempo em desequilíbrio, uma série de forças anormais começa a atuar sobre todo o corpo. Essas forças causam compressões, torções e estiramentos de músculos, articulações, ligamentos e fáscias gerando vários desconfortos (dores, câimbras, enrijecimentos, contraturas e fadiga) com repercussão imediata sobre a eficiência dos movimentos nas regiões afetadas. Em longo prazo, essas alterações podem produzir problemas articulares e alterações bioquímicas e circulatórias.

Por outro lado, a ação de tocar um instrumento musical é uma atividade física e, portanto, também requer uma prontidão motora e muscular. Tocar um instrumento de sopro requer atenção em diversos aspectos, pois envolve o domínio técnico de questões extremamente complexas como a sustentação do instrumento, a respiração, a produção do som, o vibrato, dentre outras coisas. É de nosso corpo que partem todos os comandos para que um som seja articulado, para que uma obra musical possa ser executada. Se esse corpo apresenta problemas posturais de qualquer ordem, certamente 0 ato de tocar se tornará muito mais difícil e, às vezes, até penoso.

Os comprometimentos físicos advindos de uma postura inadequada podem trazer consequências prejudiciais à performance da flauta como 0 aparecimento de dores, enrijecimentos, contraturas, limitação dos movimentos articulares, diminuição da resistência muscular. Tudo isso acaba por prejudicar seriamente a qualidade desta performance e a progressividade no aprendizado do instrumento.

Vale salientar que os estudos sobre saúde do músico são recentes, notadamente aqueles que propõem ações preventivas em relação aos desconfortos físico-posturais inerentes à performance. Dois tipos de ações preventivas têm sido propostas: (1) as que preconizam a utilização de acessórios e adaptações na flauta e (2) as que propõem que a prevenção seja 
decorrência de uma melhor consciência técnica e postural. Em nossa opinião os dois tipos de propostas são complementares, mas o desenvolvimento de uma consciência crítica técnico-postural é prioritário e condição sine qua non para a prevenção eficaz dos desconfortos físico-posturais dos músicos.

As atitudes e práticas preventivas fazem parte do cotidiano dos esportistas já há algum tempo. Os músicos devem buscar um caminho semelhante, mas, infelizmente, eles só se preocupam com seu corpo quando sentem dor. Seria ideal que, antes do aparecimento de qualquer desconforto, o instrumentista investisse em atividades que desenvolvam a consciência corporal, a fim de evitar futuros transtornos decorrentes da performance do instrumento. A prática de esportes, de alongamentos, de técnicas posturais (Técnica de Alexander, por exemplo) associados a uma alimentação regrada e um sono regular deveriam fazer parte de seu cotidiano. Esses cuidados podem favorecer a qualidade da performance e a longevidade da carreira do flautista.

\section{Referências}

ACKERMANN, B. J. et al. Incidence of injury and attitudes to injury management in skilled flute players. Work. 2011; 40(3):255-9.

ALMEIDA, A. et al. The kinetics and acoustics of fingering and note transitions on the flute. Journal of Acoust Soc Am. 2009 Sep;126(3):1521-9.

AMADIO, A. C.; MOCHIZUKI, L. Aspectos biomecânicos da postura ereta: a relação entre o certo de massa e o centro de pressão. Revista portuguesa de ciência de desporto. Escola de Educação Física e Esporte, Universidade de São Paulo. v.3, n.3, p.77-83. 2003.

BARCELLOS, C.; IMBIRIBA, L. A. Alterações posturais e do equilíbrio corporal na primeira posição em ponta do balé clássico. Revista Paulista de Educação Física, v.16, n.1, p.43-52, jan./jun. 2002.

BARKER, S. Técnica de Alexander: aprendendo a usar seu corpo para obter a energia total. São Paulo: Summus, 1991.

BENJJANI, F. J. et al. Musculoskeletal and neuromuscular conditions of instrumental musicians. Archives of Physical Medicine and Rehabilitation, 77, n.4 (Apr.1996): 406-413.

BIENFAIT, M. As bases da fisiologia da terapia manual. São Paulo: Summus, 2000.

BRICOT, B. Posturologia. São Paulo: Editor Ícone. 2001.

BRODSKY, M. Peforming artists and self care. UCLA Center for East-West Medicine, Santa Monica, CA. 2006.

COSTA, C. P. Ergonomia aplicada às práticas musicais: um novo enfoque para o músico em formação. In: Anais Congresso anual da Abem, XIV, 2005. Belo Horizonte: ABEM, 2005, p.1-6.

COURY, H. G. Trabalhando sentado. São Carlos: UFSCar, 1995.

CRASKE, M. G. e CRAIG, K. D. Musical performance anxiety: the three-systems model and self-efficacy theory. Behavior Research and Therapy, n.22, v.3, p.267-280, 1984. 
D'AVILA, R. C. Algumas considerações sobre a postura para tocar flauta. Revista Pattapio online n.22.2003.Disponível em:<http://www.geocities.com/abraf.geo/pattapio22.htm>. Acesso em: 14/03/ 2005.

DAWSON, W. Upper extremity difficulties in the dedicated amateur instrumentalists. Medical Problems of Performing Artists. n.16, p.152-156, 2001.

DEBOST, M. The simple flute: from A to Z. New York: Oxford University Press, 2002.

DOMMERHOLT, J. Posture. In: Tubiana, R.; Amadio, P. C. (eds) Medical Problems of the Instrumentalist Musician (p.399-419), Londres: Martin Dunitz Lt, 2000.

DUARTE, M. et al. Effects of body lean and visual information on the equilibrium maintenance during stance. Experimental Brain Research, n.146, p.60-69, 2002.

FERREIRA, A. B. de H. Novo Dicionário da Língua Portuguesa. 2 ed. Rio de Janeiro: Editora Nova Fronteira S.A, 1986. p.1373.

FONSECA, J. G. M. Freqüência dos problemas neuromusculares ocupacionais de pianistas e sua relação com a técnica pianística: uma leitura transdisciplinar da medicina do músico. Tese de Doutorado - Universidade Federal de Minas Gerais. Faculdade de Medicina, 2007.

FONSECA, M. P. M. Os principais desconfortos físico-posturais dos Flautistas e suas implicações no estudo na performance da flauta. Dissertação (Mestrado em Música) - Escola de Música da Universidade Federal de Minas Gerais (UFMG), Belo Horizonte, 2005.

. Os fundamentos biomecânicos da postura corporal e suas implicações na performance da flauta. In: VIII Festival Internacional de Flautistas, 2008, Maringá, PR. Evento Científico da Associação Brasileira de Flautistas, 2008.

. Os principais desconfortos físico-posturais dos flautistas e suas implicações no estudo e na performance da flauta. In: Anais do III Simpósio de Cognição e Artes Musicais Internacional. Salvador: EDUFBA, 2007, v.1. p.300-304.

FRY, H. Overuse syndrome in musicians -100 years ago. The Medical Journal of Australia, $\mathrm{n}$. 145, p.620-625, 1986a.

FRY, H. Overuse syndrome of the upper limb in musicians. The Medical Journal of Australia, $\mathrm{n}$. 144, p.182-185, 1986b.

GARDINER, D. Manual de terapia por exercícios. São Paulo: Editora e Livraria Santos,1986.

GRAF, P. L. Check-up: 20 Basic Studies for Flautists. Mainz: Editora Schott, 1991.

GRANDJEAN, E. Manual de ergonomia: adaptando o trabalho ao homem. Tradução: João Pedro Stein. $4^{\underline{a}}$ edição. Porto Alegre: Artes Médicas, 1998.

HARRISON, H. How to play the flute. New York: Saint Martin's Press, 1983.

HORAK, F. B. et al. Postural orientation and equilibrium. In: Rowell, L. B.; Shepard, J. T. (eds.) Handbook of physiology. New York, Oxford University Press, 1996.

KENDALL, F. P. et al. Músculos: provas e funções. São Paulo: Editora Manole, 1995.

KIMACHI, R. Flauta sem Mistérios. Revista Weril número 140, São Paulo, 2002. Disponível em: < www.weril.com.br/dicas.asp?area=5>. Acesso em: 14/03/2005.

KOPPEJAN, S. et al. Hand and arm problems in flautists and a design for prevention. Erasmus MC, University Medical Center Rotterdam, Dept. of Biomedical Physics and Technology.49 (3): 
316- 22.2006. Disponível em: <http://www.ncbi.nlm.nih.gov/pubmed/16540442>. Acesso em: 23/05/2012.

LIDA, I. Ergonomia: projeto e produção. 2ª̣ed. São Paulo: Ed. Edgar Blücher Ltda, 2005.

MATHIEU, M. C. Gestes et postures du flûtiste. Traversière Magazine. Saint-Claire sur Epte, v. 80. p.41-48, set. 2004.

MCGILL, S. Low back disorders: evidence-based prevention and rehabilitation. Canadá: Human Kinetics, 2002.

MENEGATTI, A. C. B. Avaliação biomecânica dos ajustes posturais em idosos caidores. Dissertação de mestrado - Escola de Educação Física e Esporte da USP. São Paulo, 2011.

MERRIMAN, L. et al. A focal movement disorder of the hand in six pianists. Medical Problems of Performing Artists, n.1:1, p.17-19, 1986.

MORO, A. R. P. Análise biomecânica da postura sentada: uma abordagem ergonômica do mobiliário escolar. Tese de Doutorado. Santa Maria - Rio Grande do Sul, 2000. Disponível em: http://www.efdeportes.com/efd85/ergon.htm

MOYSE, M. 24 Petit etudes melodiques. Paris: Alphonse Leduc Editions Musicales, 1932.

MOYSE, M. Enseignement complet de la flute. Paris: Alphonse Leduc Editions Musicales, 1934.

NEUMANN, D. A. Cinesiologia do aparelho musculoesquelético: fundamentos para a reablitação física. Rio de Janeiro: Editora Guanabara, 2006.

NORRIS, R. The Musician's Survival Manual: a guide to prevent and treating injuries in instrumentalists. 3 ed. Saint Louis: Ed. ICSOM, 1997.

PAUL, B.; HARRISON, C. The Athletic Musician: a guide to playing without pain. Edição ilustrada. New York: Scarecrow Press, 1999.

PEARSON, L. Body mapping for flutists. Columbus: Andover Education, 2002.

PEQUINI, S. M. Ergonomia aplicada ao design de produtos: um estudo de casos sobre o design de bicicletas. São Paulo: Fau-Usp, 2005.

QUANTZ, J. J. Essay of a Method for Playing The Transverse Flute. London: Faber and Faber, 1966.

RANEVSKY, E. K. A embocadura na flauta transversa: como entender e dominar. 1ae edição. Rio de Janeiro: Eugênio Kundert Ranevsky, 1999.

ROSSET, L. J. New tools for the assessment of the embouchure's biomechanics. Internacional Trumpet Guild J, p.51-53, v.81,2005.

RUMAQUELLA, M. et al. Os efeitos da postura sentada na coluna vertebral: uma revisão. Anais do 8o Congresso Brasileiro de Pesquisa e Desenvolvimento em Design, p.4142-46, 2008.

SAKAI, N. Hand pain attributed to overuse among professional pianists: a study of 200 cases. Medical Problems of Performing Artists, n.17:4, p.178-180, 2002.

SANTIAGO, P. F. O impacto da Técnica Alexander na atuação de músicos instrumentistas. In: Encontro Nacional da Abem, XVII. São Paulo, 2008. 
SANTIAGO, P. F. A perspectiva da Técnica Alexander sobre os problemas físicos da performance pianística. In: Congresso anual da Anppom, XVI. Rio de Janeiro: Unirio, 2005, p.10-11.

SANTIAGO, P. F. An exploration of the potential contributions of the Alexander Technique to piano pedagogy. PhD Thesis, Institute of Education, University of London, 2004.

SANTIAGO, P. F. Potenciais contribuições da Técnica Alexander para a pedagogia pianística. In: Congresso anual da Anppom, XVI. Brasília: UNB. 2006. p.1-11.

SANTIAGO, P. F. The Application of Alexander Technique Principles to Piano Teaching for Beginners. London: Masters Dissertation, Institute of Education, University of London, 2001.

SHENK, D. The genius in all of us: why everything you've been told about genetics, and IQ is wrong. Rio de Janeiro: Jorge Zahar, 2010.

SOUCHARD, P. E. Respiração. Tradução de Ângela Santos. São Paulo: Summus, 1989.

STEPTOE, A.; FIDLER, H. Stage fright in orchestral musicians: A study of cognitive and behavioral strategies in performance anxiety. The British Journal of Psychology, n.78, p.241249, 2001.

STEPTOE, A. Stress, coping and stage fright in professional musicians. Psychology of Music, $n$. 17, p.3-11, 1989.

TAFFANEL, P.; GAUBERT, P. Méthode Complète de Flûte. Paris: Editions Musicales Alphonse Leduc, 1958.

THOMPSON, L. A. Risk factors for flute-related pain among high school and college student. Dissertation prepared for the degree of doctor of musical arts. University of North Texas, May 2008.Disponível em: http://digital.library.unt.edu/permalink/meta-dc-6044:1.

VALENTINE, E. et al. The effects of lessons in the Alexander Technique on music performance in high and low stress situations. Psychology of Music, n.23, p.129-141, 1995.

VISENTIN, P.; SHAN, G. The Kinetic Charactermance: an examination of internal loads as a function of tempo. Medical Problems of Performing Artists, 18(3): 91-97, 2003.

WARRINGTON, J. et al. Upper-extremity problems in musicians related to age. Medical Problems of Performing Artists, n.17, p.131-134, 2002.

WILLIAMON, A.; THOMPSON, S. Awareness and incidence of health problems among conservatoire students. Psychology of Music, 34(4): 411-430. 2006.

WILLIAMON, A. Musical Excellence: Strategies and Techniques to Enhance Performance. Oxford: Oxford University Press. 2004.

WILSON, F.R. Acquisition and loss of skilled movement in musicians. Semin Neurol; 9: 146151. 1989.

WURZ, H. Querflötenkunde. Baden-Baden: Dr. Klaus Piepenstock, 1998.

WYNN, P. C. B. Managing the physical demands on musical performance. In: Williamon A. (ed) Musical Excellence: Strategies and Techniques to Enhance Performance, p.41-60. Oxford: Oxford University Press, 2004.

ZAZA, C. Playing-related musculoskeletal disorders in musicians: systematic review of incidence and prevalence. Canadian Medical Association Journal, 158(8): 1019-1025. 1998. 
Marcelo Parizzi, flautista nascido em Belo Horizonte, é professor de flauta transversal e flauta doce da Universidade Federal de São João del Rei. É doutorando no programa de Pós Graduação em Ciências Aplicadas à Saúde do Adulto pela Escola de Medicina da UFMG, mestre em performance pela Escola de Música da UFMG e desenvolve pesquisa voltada à saúde do músico, priorizando os problemas técnico-posturais dos instrumentistas de sopro. Em 2004, foi o único representante da América Latina a ter participação ativa na Master Class Internacional, na Suíça, ministrada pelo flautista James Galway, fazendo parte de um grupo de 20 flautistas escolhidos no mundo inteiro. Em 2006, apresentou-se com o pianista Phillip Moll e com a soprano Yuko Takemichi. Apresenta-se regularmente com o pianista João Gabriel Marques (MG).

Francisco Eduardo Costa Cardoso possui graduação em Medicina pela Escola de Ciências Médicas de Alagoas (1986), mestrado (1991) e doutorado (1994) em Biologia Celular pela Universidade Federal de Minas Gerais. Fez Residência Médica em Neurologia no Hospital das Clínicas da UFMG (19881991) e Clinical Post-Doctoral Fellowship (1991-1993) no Parkinson's Disease Center and Movement Disorders Clinic, Baylor College of Medicine, Houston, TX, EUA, sob a supervisão de Joseph Jankovic MD (1991-1993). Atualmente é Professor Titular (Departamento de Clínica Médica - Neurologia) da Universidade Federal de Minas Gerais. Tem experiência na área de Medicina, com ênfase em Neurologia, atuando principalmente nos seguintes temas: doença de Parkinson, coréia de Sydenham e outras manifestações neurológicas de febre reumática, anticorpos anti-núcleos da base, coréias em geral e outros distúrbios do movimento.

Antônio Carlos Guimarães possui graduação em Musica pela Universidade Federal de Minas Gerais (1990), mestrado em Master of Music - University of New México (1995) e doutorado em Doctor of Musical Arts - University of lowa (2003). Atualmente é professor adjunto do Departamento de Música da Universidade Federal de São João Del-Rei. 